\title{
Microstrip Antennas: Rectangular, Circular \&t U-Shape: Performance Comparison
}

\author{
Nishant M. Borkar ${ }^{1 *}$ and Pallavi K. Parlewar ${ }^{2}$ \\ ${ }^{1,2}$ Shri Ramdeobaba College of Engineering and Management, Nagpur
}

\section{ABSTRACT}

In this paper a performance evaluation of Microstrip Patch antenna is discussed. Theoretically various shapes of microstrip antenna can be designed, simulated and fabricated. But performance point of view Rectangular, Circular and U-shaped microstrip patch antenna are widely used in various microwave applications. Hence these three microstrip antennas are compared in this paper. The most widely used application of these antennas are in ISM Band. Hence $2.45 \mathrm{GHz}$ frequency is selected here in this paper for simulation and evaluation purpose for comparison. The commonly available and cheapest substrate FR4 (Flame Retardant) Epoxy material is selected commonly for these three antennas. All structures are simulated using HFSS 13 version software. Performance is judged depending upon parameters such as return loss, gain and directivity of these antennas.

\section{KEY WORDS: MICROWAVE, RADIO, MEDICAL IMAGING, SUBSTRATE, VSWR, IMPEDANCE}

\section{INTRODUCTION}

Microwave and optical communication integrated circuits requires a compact, light weight and cheaper manufacturing antennas (Wong, 2003). Although low gain and narrow bandwidth are the limitations of these antennas, can be circumvented by implementing bandwidth and gain improvement techniques in microstrip antenna also with some modification in physical parameters of the antennas (Bankey and Kumar, 2015). These antennas are widely used in various applications starting from bar code sensors to mobile telecommunications, including medical application such as hyperthermia, imaging, etc. The performance of these antennas can also be improved by using various other techniques such as adding parasitic elements, modifying

\section{ARTICLE INFORMATION}

*Corresponding Author: borkarnm1@rknec.edu

Received 19th Oct 2020 Accepted after revision 29th Dec 2020

Print ISSN: 0974-6455 Online ISSN: 2321-4007 CODEN: BBRCBA

Thomson Reuters ISI Web of Science Clarivate Analytics USA and Crossref Indexed Journal

\section{Clarivate
Analytics}

NAAS Journal Score 2020 (4.31)

A Society of Science and Nature Publication,

Bhopal India 2020. All rights reserved.

Online Contents Available at: http//www.bbrc.in/

Doi: http://dx.doi.org/10.21786/bbrc/13.14/69 thickness of the substrate, altering substrate material and several other techniques which effectively modifying shape of the patch(Vaid and Agrawal, 2014) (Elo, Zulkifli and Rahardjo, 2017).

Depending upon applications and available space to fit in the patch antenna can be designed in various geometrical shapes, more over depending upon shape and size required gain, radiation pattern, directivity of antenna can be controlled to a required level up to some extent (Khan, Riaz and Bilal, 2016). Some of popular shapes of patch antennas are rectangular, circular, elliptical, U-shape, triangular and various combinations of all above in form of sector antennas like disc sector, circular ring for improvement of desired parameters(Giauffret, Laheurte and Papiernik, 1997).

In the coming paragraphs three microstrip patch antenna configurations namely simple rectangular, notch feed circular and U-shape antennas are compared depending upon their simulation and characterization results. All these three configurations are designed for contact feeding method where power is directly given to a patch, in general there are two types of feeding techniques for microstrip antennas: contacting and non-contact feeding (Bisht et al., 2014) have their own benefits and

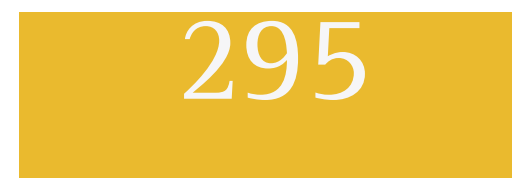


limitations. Other than telecommunication applications, short range low power device applications internationally allocated a dedicated an ISM band. One range in this band is $2.4-2.5 \mathrm{GHz}$ centered at $2.45 \mathrm{GHz}$. ISM is a acronym for Industrial, Scientific and Medical band and have applications such as microwave ovens, cordless

Figure 1: Microstrip Patch Antenna Major Geometrical Shapes

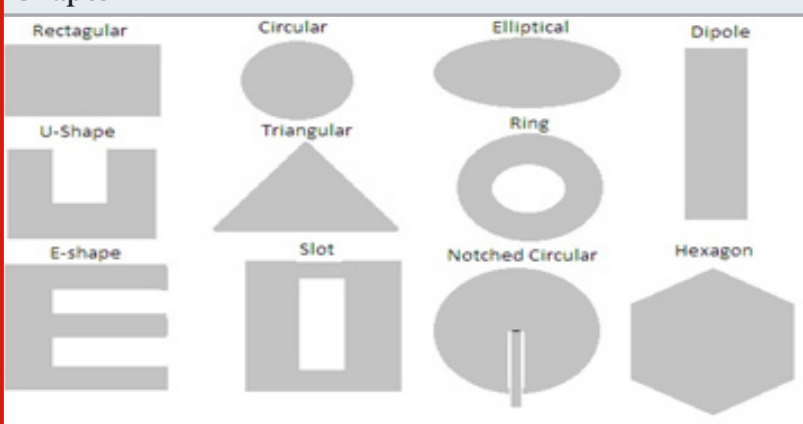

Table 1. Various medical applications of microwave antennas in ISM bands

\begin{tabular}{l|c|c|}
\hline $\begin{array}{l}\text { Thermal } \\
\text { Treatment }\end{array}$ & Microwave Imaging & Biotelemetry \\
\hline Hyperthermia & $\begin{array}{c}\text { Breast Cancer } \\
\text { Detection Antennas }\end{array}$ & $\begin{array}{c}\text { Wearable } \\
\text { Antennas }\end{array}$ \\
\hline & $\begin{array}{c}\text { Flexible Antennas for } \\
\text { Breast cancer detection } \\
\text { Brain Stroke } \\
\text { Detection Antennas } \\
\text { Brain Tumor } \\
\text { Detection Antennas }\end{array}$ & $\begin{array}{c}\text { Antennas } \\
\text { Antable }\end{array}$ \\
&
\end{tabular}

phones, Bluetooth, near field communication, door openers, baby monitors, Wi-Fi networks. Other than these applications there are various medical applications where this ISM band can be used to treat certain ailments and diseases using antennas operating in this band (Kaur et al., 2015). Various medical applications of Antennas operating in ISM band are given below table.

Due to this reason there is an increased interest in microwave medical imaging systems, which resulted in development of various types of antenna which are suitable for this application. To design the antenna for this application, the electromagnetic (EM) modelling and required high frequency computation is required to perform in software such as HFSS or CST Microwave studio FEKO etc. The performance of the antennas is typically simulated separately from the whole Microwave Imaging System (MIS) in these high frequency structural simulator softwares and then these simulated structures are then fabricated using CAD machines. Even after perfect simulation after fabrication the simulated and actual characterization results of a fabricated antenna differ by some margin.
This difference in simulated results and actual characterization results have many reasons such as quality of dielectric substrate, quality of conducting patch, errors in physical implementations, etc (Durney and Iskander, 1988). For this applications Rectangular Microstrip Patch antenna, U-shape patch antenna and notched circular centre fed antenna operating at 2.45 $\mathrm{GHz}$ (ISM Band) are found suitable and hence simulated in HFSS software version 13. Simulation is followed by actual physical implementation i.e. fabrication of these devices and lastly all of these three types of antennas are characterized and results are matched with their simulated results.

Rectangular Microstrip Patch Antenna: Simulation: First a basic rectangular microstrip patch antenna is designed as follows. Physical Dimensions of Patch Length $=38$ $\mathrm{mm}$, Patch Width $=29.5 \mathrm{~mm}$, Feed Length $=15 \mathrm{~mm}$, Feed Width $=2 \mathrm{~mm}$, Ground Plane $60 \mathrm{~mm}$ x $60 \mathrm{~mm}$ Material FR4 Epoxy, Dielectric constant $=4.4$.

Figure 1: Rectangular Patch Antenna HFSS Simulated 3D Modeler: Front and Back view

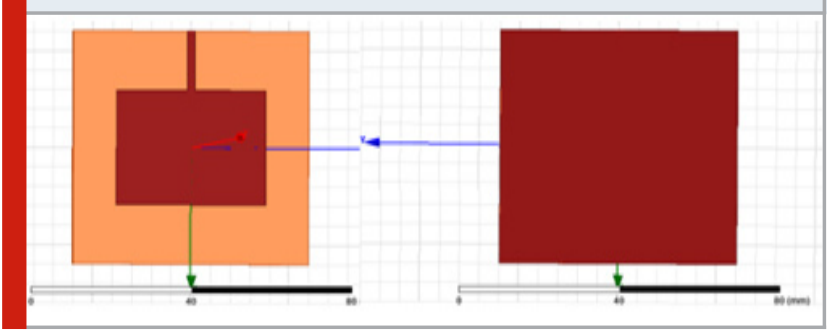

Figure 2: Rectangular Patch Antenna S11 Plot: Centre Frequency $=2.450 \mathrm{GHz}$ \&t S11 $<-25 \mathrm{~dB}$

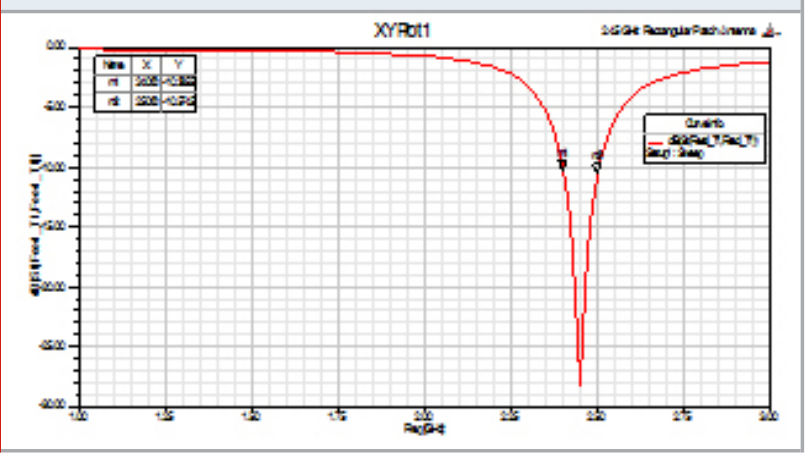

Figure 3: Rectangular Patch Antenna 3D Polar Plot Gain 2.17 dB - Radiation Pattern

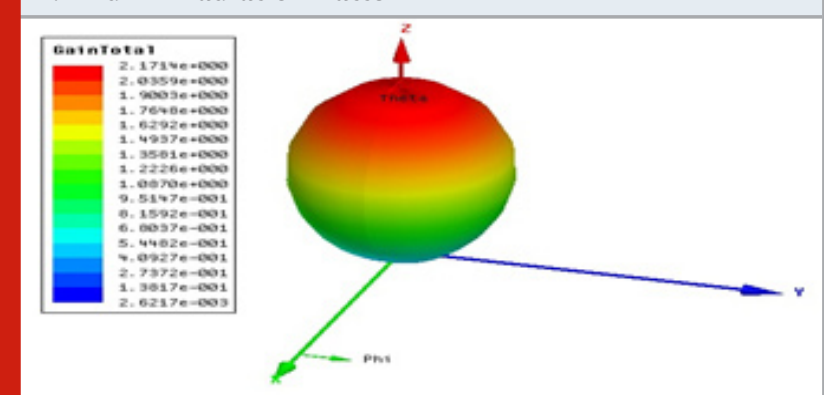




\section{Fabrication of Rectangular Patch Antenna}

Figure 4: Fabricated Rectangular Patch Antenna: Front; Back View

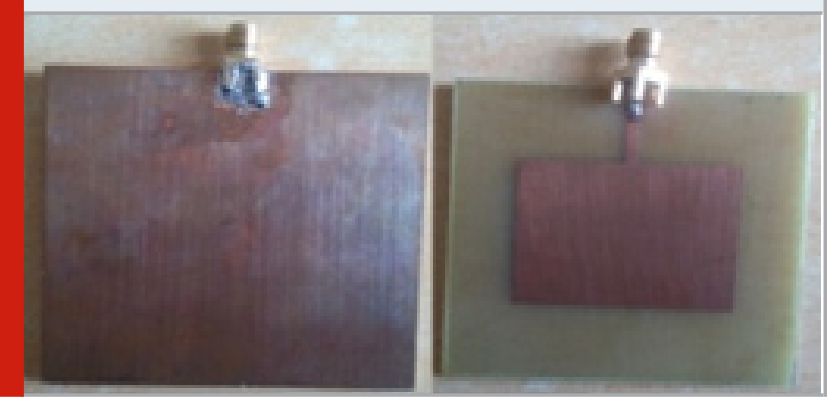

Figure 5: Rectangular Patch Antenna S11 Plot on VNA

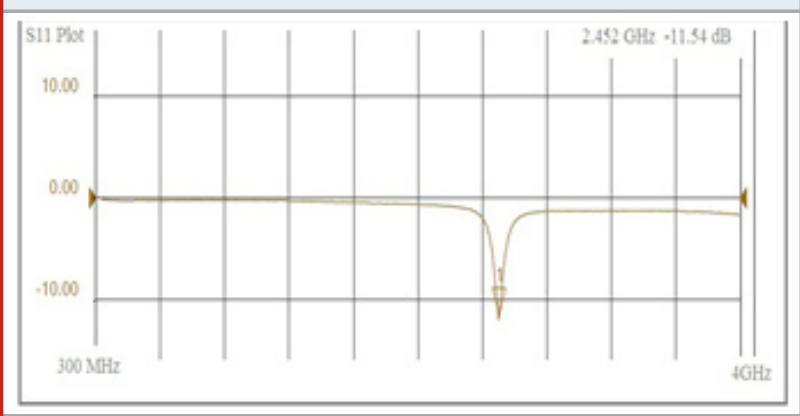

Figure 6: Rectangular Patch Antenna Smith Chart Plot

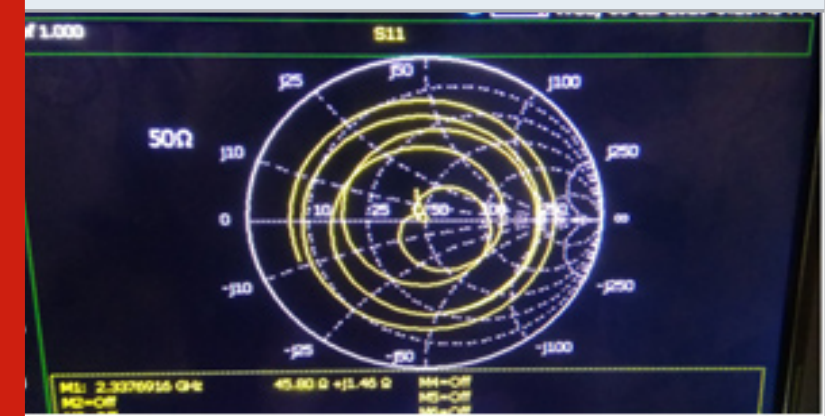

Table 2. Comparative results for Rectangular Patch antenna

\begin{tabular}{|l|c|c|}
\hline $\begin{array}{l}\text { Rectangular } \\
\text { Patch Antenna }\end{array}$ & $\begin{array}{c}\text { Simulation } \\
\text { Parameter }\end{array}$ & $\begin{array}{c}\text { Characterization } \\
\text { Parameters }\end{array}$ \\
\hline Centre Frequency & $2.45 \mathrm{GHz}$ & $2.452 \mathrm{GHz}$ \\
\hline S11 Band width & $0.1 \mathrm{GHz}$ & $0.09 \mathrm{GHz}$ \\
\hline VSWR Band width & $0.11 \mathrm{GHz}$ & $0.1 \mathrm{GHz}$ \\
\hline Impedance & $50 \Omega$ & $(45.80+\mathrm{j} 1.46) \Omega$ \\
\hline
\end{tabular}

Characterization of Rectangular Patch Antenna on Vector Network Analyzer (VNA) for S11 parameter
Figure 7: Model Simulation of Circular patch antenna

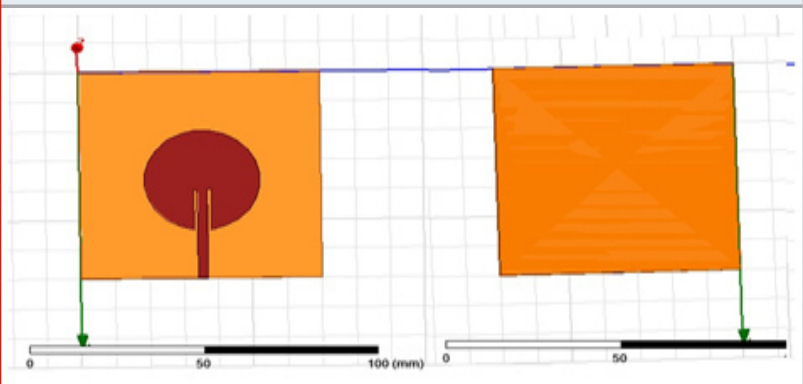

Figure 8: $\mathrm{S} 11$ Plot $\mathrm{BW}<-10 \mathrm{~dB}=0.11 \mathrm{GHz}$

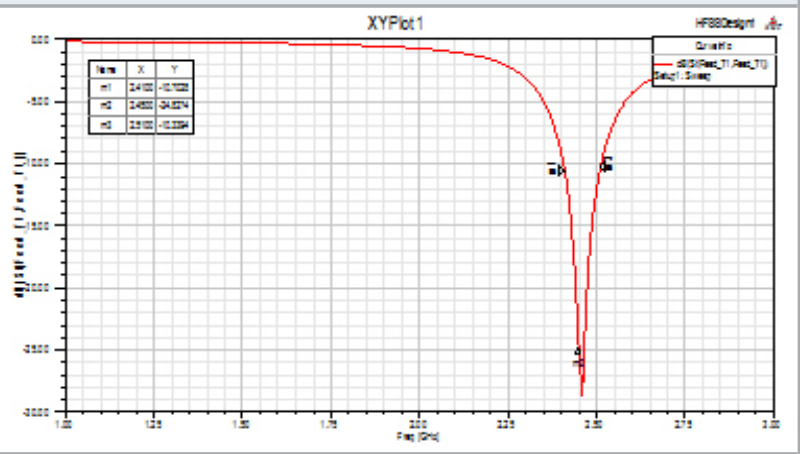

Figure 9: VSWR Plot $<3 \mathrm{~dB} \mathrm{BW}=0.06 \mathrm{GHz}$

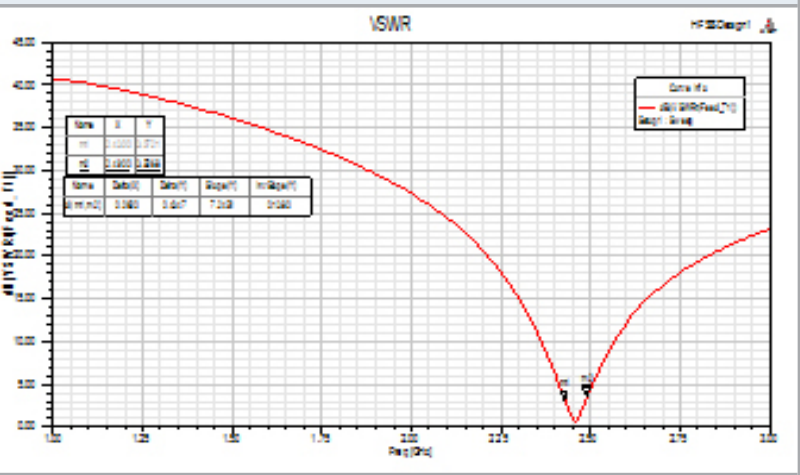

Figure 10: 2D Radiation Pattern Plot

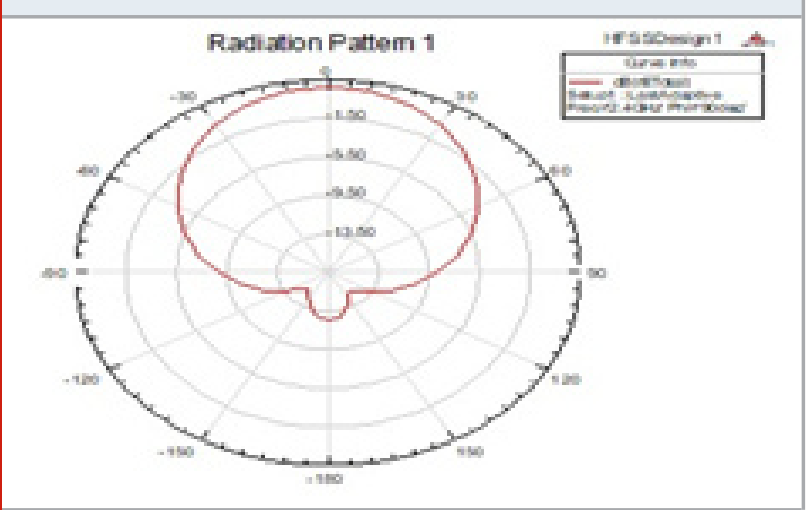


Figure 11: 3D Gain Plot, maximum gain of $4.53 \mathrm{~dB}$

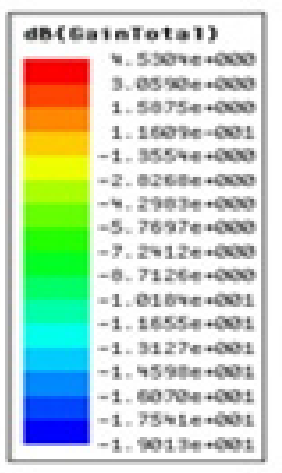

Circular Microstrip Patch Antenna at $2.45 \mathrm{GHz}$

Characterization of Circular Patch Antenna on Vector Network Analyzer (VNA) for S11 parameter

Figure 12: Circular Patch Antenna S11 VNA Plot

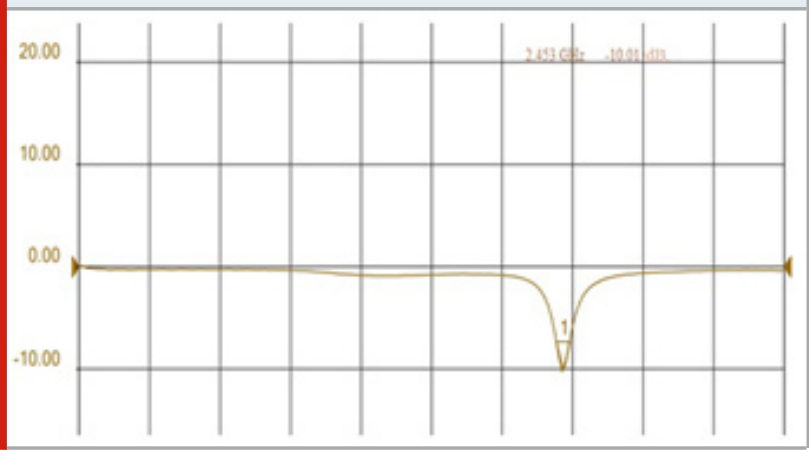

Figure 13: Circular Patch Antenna fabrication

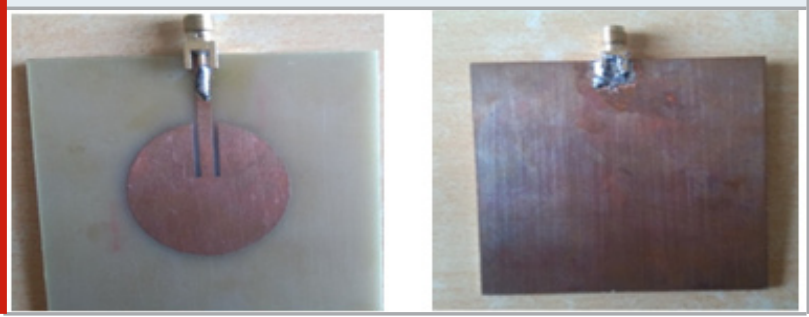

Table 3: Comparative results for Circular Patch antenna

\begin{tabular}{|l|c|c|}
\hline $\begin{array}{l}\text { Circular Patch } \\
\text { Antenna }\end{array}$ & $\begin{array}{c}\text { Simulation } \\
\text { Parameter }\end{array}$ & $\begin{array}{c}\text { Characterization } \\
\text { Parameters }\end{array}$ \\
\hline Centre Frequency & $2.45 \mathrm{GHz}$ & $2.453 \mathrm{GHz}$ \\
\hline S11 Band width & $0.11 \mathrm{GHz}$ & $0.1 \mathrm{GHz}$ \\
\hline VSWR Band width & $0.06 \mathrm{GHz}$ & $0.05 \mathrm{GHz}$ \\
\hline Impedance & $50 \Omega$ & $(45.85+\mathrm{j} 1.41) \Omega$ \\
\hline
\end{tabular}

Simulation of U-Shaped Patch Antenna
Figure 14: U-shape Patch Antenna HFSS Simulated 3D Modeler: Front and Back view

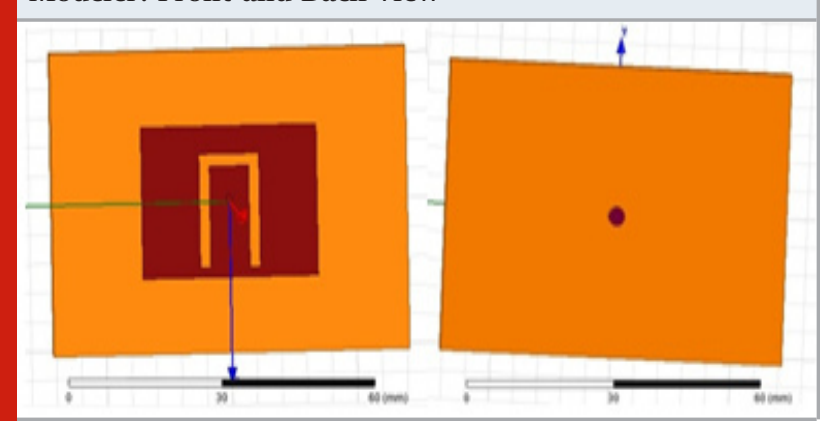

Figure 15: S11 Plot $\mathrm{BW}<-10 \mathrm{~dB}=0.16 \mathrm{GHz}$

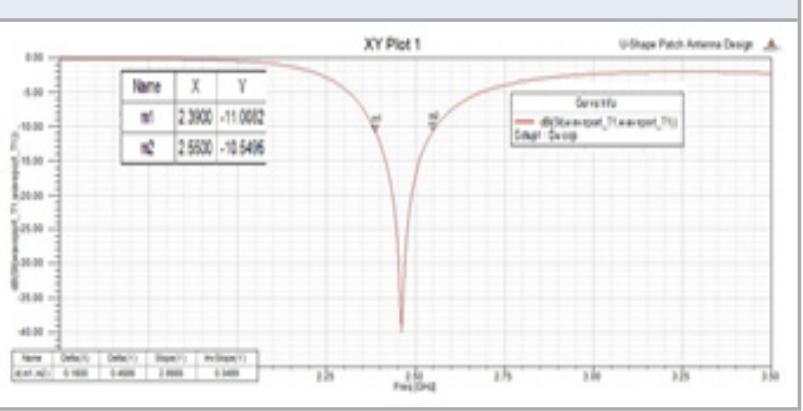

\section{Characterization of U-Shaped Patch Antenna}

Figure 16: Fabricated U-shaped Patch Antenna: Front; Back View

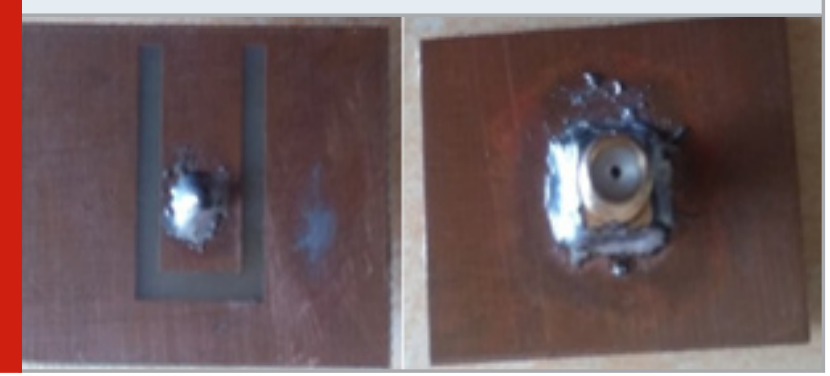

Figure 17 : U-shaped Patch Antenna S11 Plot on VNA

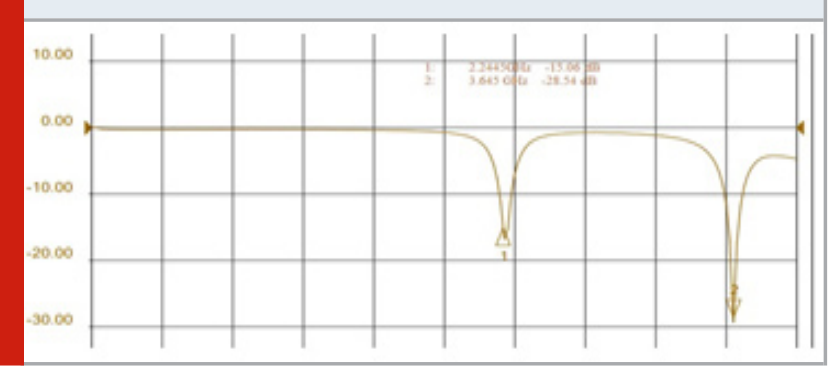


Table 4. Comparative results for U-shaped Patch antenna

\begin{tabular}{|l|c|c|}
\hline $\begin{array}{l}\text { U- Shaped } \\
\text { Patch Antenna }\end{array}$ & $\begin{array}{c}\text { Simulation } \\
\text { Parameter }\end{array}$ & $\begin{array}{c}\text { Characterization } \\
\text { Parameters }\end{array}$ \\
\hline Centre Frequency & $2.45 \mathrm{GHz}$ & $2.453 \mathrm{GHz}$ \\
\hline S11 Band width & $0.16 \mathrm{GHz}$ & $0.15 \mathrm{GHz}$ \\
\hline VSWR Band width & $0.12 \mathrm{GHz}$ & $0.1 \mathrm{GHz}$ \\
\hline Impedance & $50 \Omega$ & $(49.80+\mathrm{j} 1.15) \Omega$ \\
\hline
\end{tabular}

\section{CONCLUSION}

From above simulation and fabrication results it can be concluded that though patch antenna have inherent bandwidth and gain limitations, it can be modified up to certain extent by using different shapes like circular and U-Shape patch antenna. In above simulations we have got maximum S11 band width for U-Shape patch antenna at the cost of some complexity in the design during simulation and fabrication. Hence U-shaped patch antenna is a suitable device for medical applications.

\section{REFERENCES}

Bankey, V. and Kumar, N. A. (2015) 'Design and performance issues of Microstrip antennas', International Journal of Scientific and Engineering Research, 6(3), pp. 1572-1580. doi: 10.14299/ijser.2015.03.008.

Bisht, S. et al. (2014) 'Study The Various Feeding Techniques of Microstrip Antenna Using Design and Simulation Using CST Microwave Studio', International Journal of Emerging Technology and Advanced
Engineering, 4(9), pp. 318-324.

Durney, C. H. and Iskander, M. F. (1988) 'Antennas for Medical Applications', in Antenna Handbook. Boston, MA: Springer US, pp. 1729-1788. doi: 10.1007/978-14615-6459-1_24.

Elo, Y. La, Zulkifli, F. Y. and Rahardjo, E. T. (2017) 'Design of wideband microstrip antenna with parasitic element for 4G/LTE application', in 2017 15th International Conference on Quality in Research (QiR) : International Symposium on Electrical and Computer Engineering. IEEE, pp. 110-113. doi: 10.1109/QIR.2017.8168463.

Giauffret, L., Laheurte, J. M. and Papiernik, A. (1997) 'Study of various shapes of the coupling slot in cpw-fed microstrip antennas', IEEE Transactions on Antennas and Propagation, 45(4), pp. 642-647 doi: 10.1109/8.564090.

Kaur, G. et al. (2015) 'Antennas for biomedical applications', Biomedical Engineering Letters, 5(3), pp. 203-212. doi: 10.1007/s13534-015-0193-z.

Khan, A. Q., Riaz, M. and Bilal, A. (2016) 'Various Types of Antenna with Respect to their Applications : A Review', International Journal of Multidisciplinary Sciences and Engineering,7(3), pp. 1-8.

Vaid, V. and Agrawal, S. (2014) 'Bandwidth optimization using fractal geometry on rectangular microstrip patch antenna with DGS for wireless applications', in 2014 International Conference on Medical Imaging, m-Health and Emerging Communication Systems (MedCom). IEEE, pp. 162-167. doi: 10.1109/MedCom.2014.7005996.

Wong, K.-L. (2003) 'Broadband Microstrip Antennas', in Compact and Broadband Microstrip Antennas. New York, USA: John Wiley \& Sons, Inc., pp. 232-278. doi: 10.1002/0471221112.ch7. 